\title{
Preparation of Aluminum Nitride Powder from Aluminum Chloride/Ethylenediamine Precursor
}

\author{
Takeo HYODO, Masataka KANO, Yasuhiro SHIMIZU and Makoto EGASHIRA \\ Department of Materials Science and Engineering, Faculty of Engineering, Nagasaki University, 1-14, Bunkyo-machi, Nagasaki-shi $852-8521$ \\ 塩化アルミニウムーエチレンジアミン系前駆体からの窒化アルミニウムの調製 \\ 兵頭健生·加納正挙·清水康博 ·江頭 誠 \\ 長崎大学工学部材料工学科, 852-8521 長崎市文教町 1-14
}

\begin{abstract}
Aluminum nitride powder was prepared by calcination of an organic precursor, which was synthesized by adding aluminum chloride powder in an ethylenediamine solvent in a dry $\mathrm{N}_{2}$ atmosphere. It was confirmed from X-ray diffraction analysis and Fourier transform infrared spectroscopy that amorphous and hexagonal AlN powders formed from the precursor after calcination at 800 and $1200^{\circ} \mathrm{C}$ for $5 \mathrm{~h}$ in flowing dry $\mathrm{N}_{2}$, respectively. Scanning electron microscopic observation revealed that the AIN crystallites obtained at $1200^{\circ} \mathrm{C}$ were less than $25 \mathrm{~nm}$ in diameter, though they easily agglomerated to form large grains of $60-100 \mu \mathrm{m}$. The particle size was comparable to the crystallite size $(\approx 17.5 \mathrm{~nm})$ calculated from the half width of the XRD (100) peak.

[Received March 30, 2001; Accepted May 23, 2001]
\end{abstract}

Key-words : Aluminum nitride, Aluminum chloride, Ethylenediamine, Organic precursor

\section{Introduction}

Aluminum nitride (AlN) is well known as an attractive material for silicon-compatible substrates with high thermal conductivity and low thermal expansion coefficient comparable to Si. AlN powder was commonly prepared by direct nitridation of metallic aluminum or carbothermal reduction of $\mathrm{Al}_{2} \mathrm{O}_{3}$. However, grinding process is indispensable for the former, resulting in an increase in oxygen content in the powder, and highly pure $\mathrm{Al}_{2} \mathrm{O}_{3}$ and high temperature are needed for the latter. To avoid such problems, some more sophisticated methods of AIN synthesis have been suggested and developed. Typical examples are nitridation of floating metallic $\mathrm{Al}$ powder in flowing $\mathrm{N}_{2}{ }^{1)}$ or that of metallic $\mathrm{Al}$ powder in $\mathrm{Ar}-\mathrm{N}_{2}$ plasma induced by $2.45 \mathrm{GHz}$ microwave ${ }^{2)}$ and reactions of metallic $\mathrm{Al}$ powder with various $\mathrm{N}$-containing materials. ${ }^{3), 4)}$ Various organic precursors have also been utilized to prepare fine AlN particles at lower temperatures. $\mathrm{AlCl}_{3} 6 \mathrm{H}_{2} \mathrm{O}$-urea, ${ }^{5)} \quad \mathrm{LiAlH}_{4}-{ }^{i} \mathrm{PrNH}_{2}$ or $\mathrm{LiAlH}_{4}-\mathrm{EtNH}_{2}$. $\mathrm{HCl},{ }^{6), 7)} \quad \mathrm{AlCl}_{3}$-trimethylphenylammonium- $\mathrm{NH}_{3},{ }^{8)} \quad \mathrm{AlCl}_{3}-$ $\mathrm{N}_{2} \mathrm{H}_{4}$-metallic $\mathrm{Li}^{9)}$ and $\mathrm{AlCl}_{3}$-glucose systems ${ }^{10)}$ were investigated as the precursors for AlN synthesis. However, these methods are not easy to be practically used, since the preparation procedures of the precursors are rather complicated, except for Refs. 5) and 10). Ethylenediamine (ED) was also used for preparing an AlN thin film on an Si substrate by Jiang et al. ${ }^{11)}$ However, they used inflammable and expensive trialkylaluminum as the $\mathrm{Al}$ source, and $\mathrm{NH}_{3}$ is indispensable as the $\mathrm{N}$ source. The use of $\mathrm{N}_{2}$, instead of $\mathrm{NH}_{3}$, is undoubtedly favorable from the view point of industrial application. In the present study, we employed an organic precursor synthesized from $\mathrm{AlCl}_{3}$ and $\mathrm{ED}$, to fabricated fine AlN particles in a $\mathrm{N}_{2}$ atmosphere.

\section{Experimental}

Anhydrous $\mathrm{AlCl}_{3}$ (Kishida Chemical Co., Ltd., reagent grade) was added in an ED (Kishida Chemical Co., Ltd., reagent grade) solvent as an $\mathrm{N}$-source at a molar ratio of $\left[\mathrm{AlCl}_{3}\right] /[\mathrm{ED}]=0.1$ in flowing dry $\mathrm{N}_{2}(99.99 \%)$ at room temperature. The temperature of the suspension increased after the addition, and then a brownish white solid product was precipitated. The solid product was filtered off and was dried at $130^{\circ} \mathrm{C}$ for about $2 \mathrm{~h}$ to remove unreacted $\mathrm{ED}$. The solid product was then calcined at 800 or $1200^{\circ} \mathrm{C}$ for $5 \mathrm{~h}$ in flowing dry $\mathrm{N}_{2}$. The powders obtained were characterized by X-ray diffraction (XRD; Rigaku, RINT-2200), Fourier transform infrared spectroscopy (FT-IR; Perkin Elmer, System 2000) and scanning electron microscopy (SEM; Hitachi, S-2250N).

\section{Results and discussion}

Figure 1 shows an XRD pattern of the organic precursor synthesized from $\mathrm{AlCl}_{3}$ and $\mathrm{ED}$. The XRD pattern of the precursor was completely different from that of $\mathrm{AlCl}_{3}$, but the compound could not be identified from the available JCPDS (Joint Committee on Powder Diffraction Standards) cards, suggesting that a new solid material was synthesized by the reaction of $\mathrm{AlCl}_{3}$ with ED. An FT-IR spectrum of the precursor is shown in Fig. 2. Since the peaks around ca. 3500 and $3400 \mathrm{~cm}^{-1}$ generally stand for asymmetric and symmetric stretching vibrations of amide and amine groups in diluted solutions, ${ }^{13}$ the absorption peaks at 3515 and $3438 \mathrm{~cm}^{-1}$ can be assigned to residual ED in the precursor.

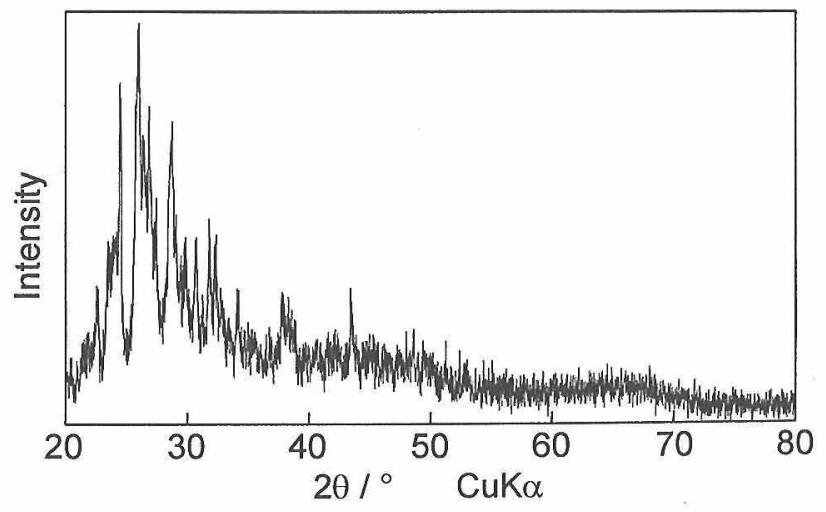

Fig. 1. XRD pattern of an organic precursor synthesized from $\mathrm{AlCl}_{3}$ and ethylenediamine. 


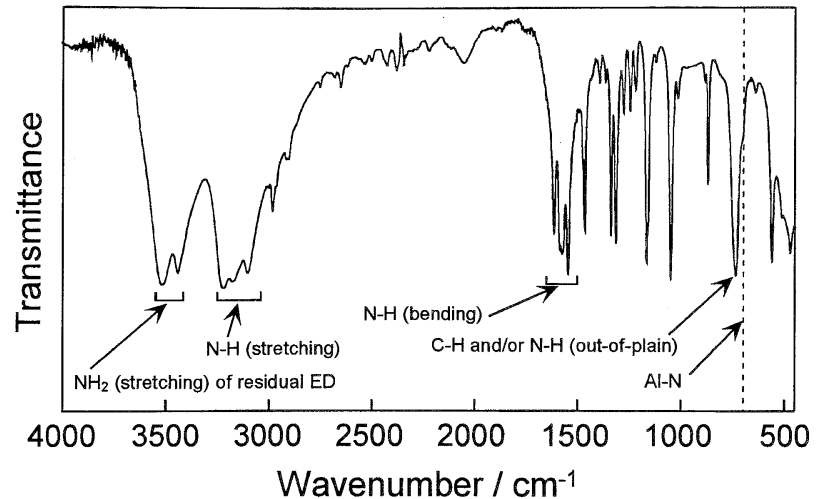

Fig. 2. FT-IR spectrum of an organic precursor synthesized from $\mathrm{AlCl}_{3}$ and ethylenediamine.

On the other hand, the peaks at 3217,3174 and $3101 \mathrm{~cm}^{-1}$ are considered to be the stretching vibrations of $\mathrm{N}-\mathrm{H}$ groups of different bonding structure involved in the precursor, such as asymmetric and symmetric stretching vibrations of secondary amines and amine salts, and multiple absorption of dimerized, oligomerized, or polymerized amides. ${ }^{13)}$ The appearance of several peaks between 1500 and $1650 \mathrm{~cm}^{-1}\left(1616,1589,1578\right.$ and $\left.1548 \mathrm{~cm}^{-1}\right)$ are assignable to $\mathrm{N}-\mathrm{H}$ bending vibrations of amine groups $\left(-\mathrm{NH}_{2}\right.$ and $-\mathrm{NH}$ ) and amine salts, ${ }^{13)}$ suggesting that the bond states around $\mathrm{N}$ atoms in the precursor are complicated. The peak at $730 \mathrm{~cm}^{-1}$ is due to a $\mathrm{CH}$ and/or NH out-of-plain vibration. A weak shoulder peak of an Al-N stretching vibration at $700 \mathrm{~cm}^{-1}$ may be the evidence of the presence of $\mathrm{Al}-\mathrm{N}$ bonds in the precursor.5),14) Thus, two kinds of $\mathrm{Al}-\mathrm{N}$ bonds may be suggested to exist in the precursor, as shown below.

1. Weak coordinate bond between $\mathrm{Al}$ and $\mathrm{N}$ (e.g., $\mathrm{Cl}_{3} \mathrm{Al}$ : $\mathrm{NH}_{2}-$ ).

2. Al-N bond formed by the reaction (e.g., $\mathrm{AlCl}_{3}+$ $\left.\mathrm{NH}_{2}-\rightarrow \mathrm{Cl}_{2} \mathrm{AlNH}-+\mathrm{HCl}\right)$

Tertiary amines, such as $\mathrm{Al}-\mathrm{N}(\mathrm{Al})-\mathrm{C}$ structure, may exist in the precursor, but it is difficult to confirm with FT-IR.

Figures 3 and 4 show XRD patterns and FT-IR spectra of the powders calcined at 800 and $1200^{\circ} \mathrm{C}$ for $5 \mathrm{~h}$, respectively. The featureless pattern shown in Fig. 3 (a) suggests that organic compounds involved in the precursor thermally decomposed or evaporated, to leave an amorphous residue after the calcination at $800^{\circ} \mathrm{C}$. In the FT-IR spectrum (Fig. 4 (a)), some absorption peaks were observed in the range of $1300-1600,1000-1300$ and $500-1000 \mathrm{~cm}^{-1}$, which were corresponding to $\mathrm{N}-\mathrm{H}$ bending, $\mathrm{C}-\mathrm{N}$ stretching and $\mathrm{N}-\mathrm{H}$ out-of-plain vibrations, respectively. In addition, a small peak of Al-N bonds was also observed around $700 \mathrm{~cm}^{-1}$. Thus, it is very likely that amorphous A1N was formed together with carbonaceous materials by the calcination of the precursor at $800^{\circ} \mathrm{C}$ in flowing $\mathrm{N}_{2}$ without using $\mathrm{NH}_{3}$. Surface hydrolysis of the formed amorphous AlN in the ambient air may be a cause of the appearance of the $\mathrm{N}-\mathrm{H}$ bending and out-of-plain vibration.

The formation of hexagonal AlN was confirmed after the calcination at $1200^{\circ} \mathrm{C}$ with the XRD analysis, as shown in Fig. 3(b). Hashimoto et al. reported that AlN powder was prepared from the mixture of $\mathrm{AlCl}_{3}$ and glucose by the calcination at temperatures above $1300^{\circ} \mathrm{C}$ in flowing $\mathrm{N}_{2} \cdot{ }^{10)}$ In this case, $\mathrm{N}$ atoms in the prepared AlN powder should come from a gas phase and this require higher temperatures. In the present study, however, AlN powder could be prepared at a lower temperature of $1200^{\circ} \mathrm{C}$, since Al-N bonds already

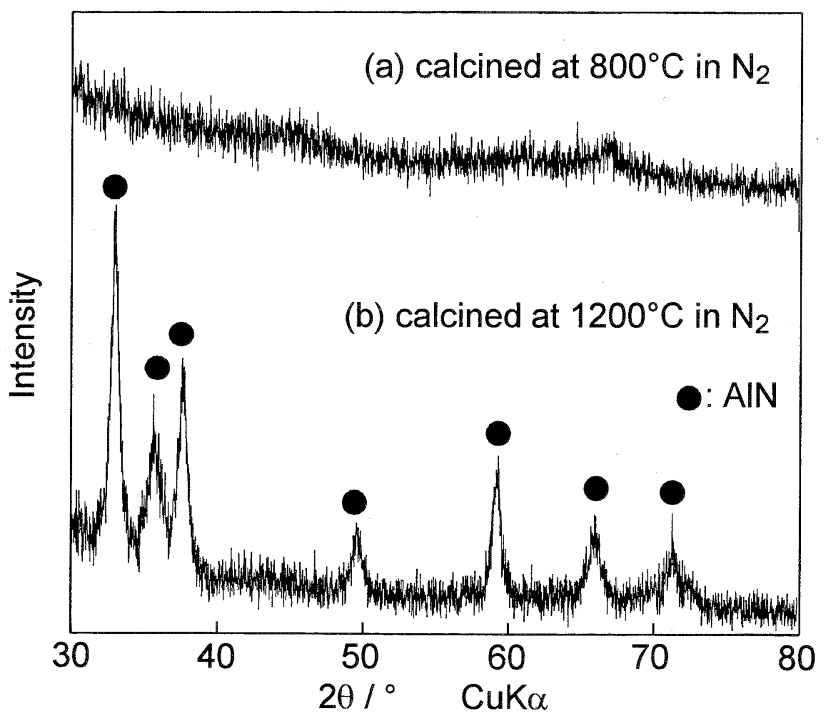

Fig. 3. XRD patterns of the products calcined at (a) $800^{\circ} \mathrm{C}$ and (b) $1200^{\circ} \mathrm{C}$ for $5 \mathrm{~h}$ in flowing $\mathrm{N}_{2}$.

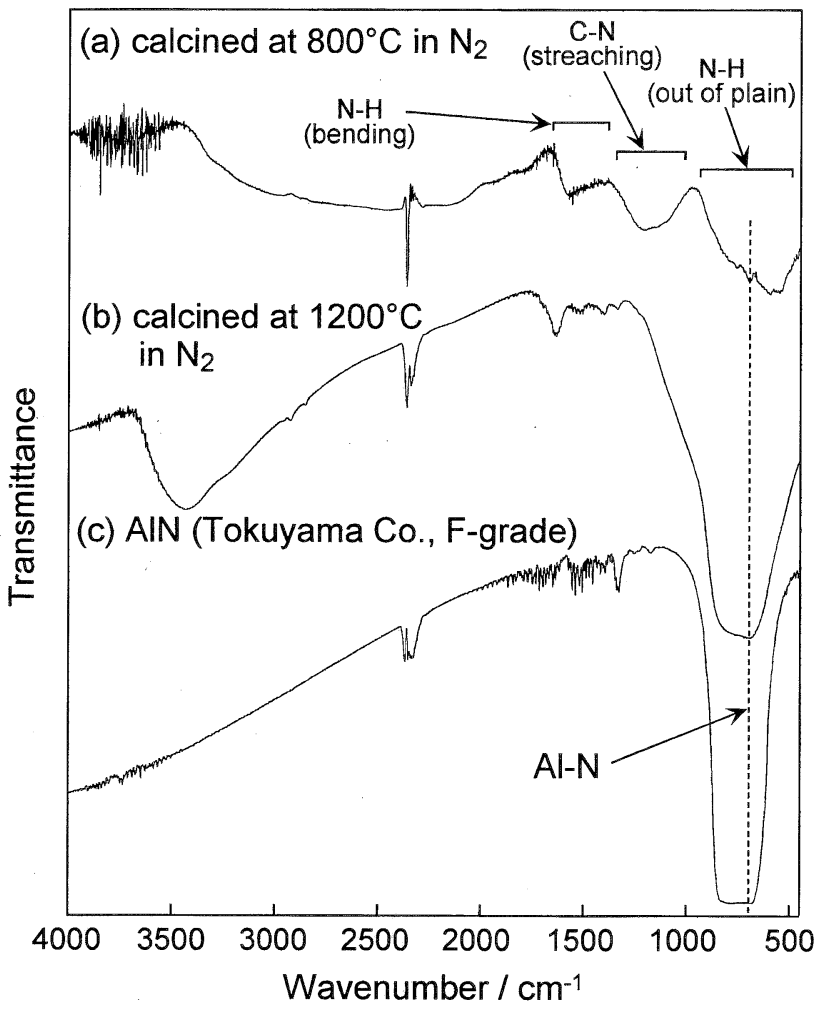

Fig. 4. FT-IR spectra of the products calcined at (a) $800^{\circ} \mathrm{C}$ and (b) $1200^{\circ} \mathrm{C}$ for $5 \mathrm{~h}$ in flowing $\mathrm{N}_{2}$, and (c) reference $\mathrm{AlN}$ powder (Tokuyama Co., F-grade).

exist in the precursor. In addition, the FT-IR spectrum shown in Fig. 4(b) quite resembled that of AlN powder from Tokuyama Co. (F-grade) in Fig. 4(c), except for the very broad peak at $3200-3600 \mathrm{~cm}^{-1}$ due to adsorbed water.

SEM photographs of the AlN powder calcined at $1200^{\circ} \mathrm{C}$ for $5 \mathrm{~h}$ are shown in Fig. 5. The size of the agglomerated grains was in the range of 60 and $100 \mu \mathrm{m}$ in diameter as shown in Fig. 5 (a), but the size of the individual fine parti- 


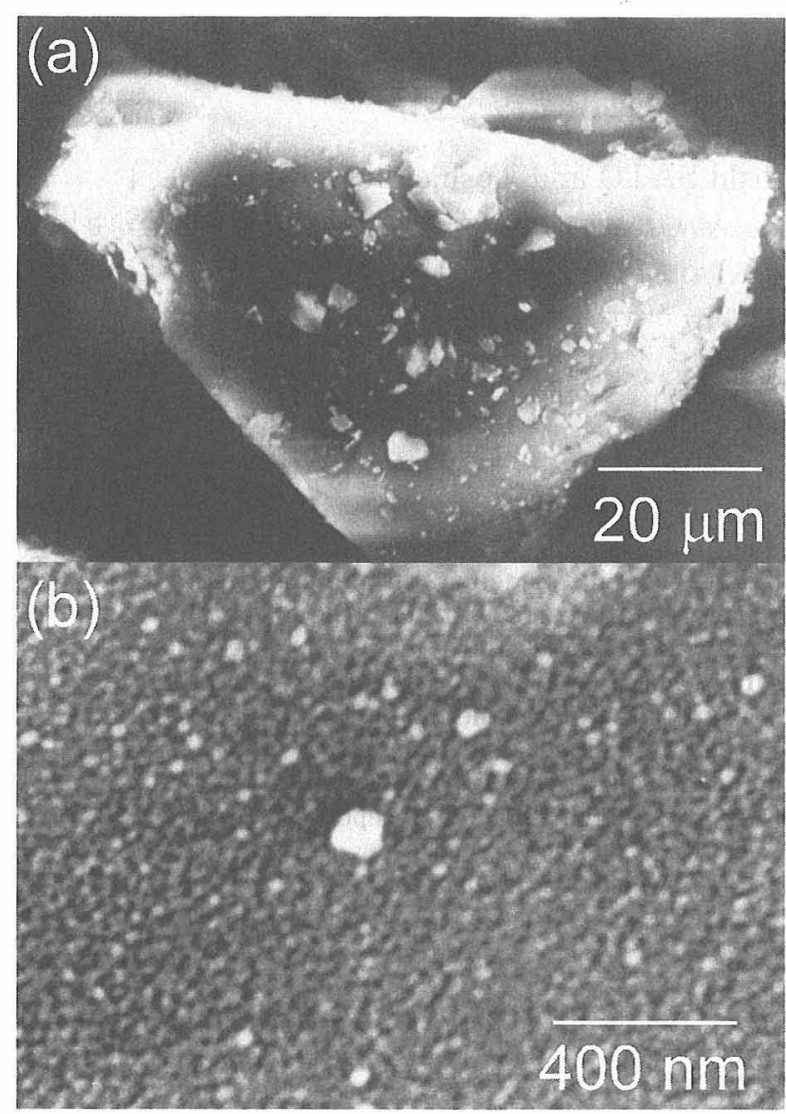

Fig. 5. SEM photographs of the product calcined at $1200^{\circ} \mathrm{C}$ for $5 \mathrm{~h}$ in flowing $\mathrm{N}_{2}$. (a) An agglomerated grain and (b) its surface.

cles was less than $25 \mathrm{~nm}$ in diameter, as shown in Fig. 5(b). This particle size was almost comparable to the crystalline size of $17.5 \mathrm{~nm}$ calculated from the half-width of the XRD (100) peak.

Thus, the organic complex synthesized from $\mathrm{AlCl}_{3}$ and $\mathrm{ED}$ was confirmed to be a novel precursor in preparing $\mathrm{AlN}$ powder. Further investigations are now in progress to modify the preparation and calcination conditions of the precursor to obtain fine AlN powder without agglomeration and to estimate the amount of impurities, especially oxygen.

\section{References}

1) Hotta, N., Meguro, T. and Komeya, K., Key Engineering Materials, 159-160, 65-70 (1999).

2) Minehira, K., Takao, Y., Shimizu, Y. and Egashira, M., Key Engineering Materials, 159-160, 59-64 (1999).

3) Bradshaw, S. M. and Spicer, J. L., J. Am. Ceram. Soc., 82 2293-300 (1999).

4) Hwang, C.-C., Weng, C.-Y., Lee, W.-C. and Chung, S.-L., Intern. J. Self-Propagating High-Temperature Synthesis, 6, 419-29 (1997).

5) Uheda, K., Takahashi, M., Takizawa, H., Endo, T. and Shimada, M., Key Engineering Materials, 159-160, 53-58 (1999).

6) Sugahara, Y., Koyama, S. and Kuroda, K., Key Engineering Materials, 159-160, 77-82 (1999).

7) Saito, Y., Sugahara, Y. and Kuroda, K., J. Am. Ceram. Soc., 83, 2436-40 (2000).

8) Carter, M. T., Donahue, W. J. and Doris, J. J., Electrochem Soc. Proc., 98-11, 187-98 (1998).

9) Kim, J. Y. and Kumta, P. N., Mater. Lett., 34, 188-95 (1998).

10) Hashimoto, N., Sawada, Y., Bando, T., Yoden, H. and Deki, H., J. Am. Ceram. Soc., 74, 1282-86 (1991).

11) Jiang, Z. and Interrante, L. V., Chem. Mater., 2, 439-46 (1990).

12) Maya, L., Adv. Ceram. Mater., 1, 150 (1986)

13) Silverstein, R. M., Bassler, G. C. and Morrill, T. C., "Spectrometric Identification of Organic Compound," 4th ed., John Wiley \& Sons (1981) pp. 123-27.

14) Wade, T., Park, J., Garza, E. G., Ross, D. B., Smith, D. M. and Crooks, R. M., J. Am. Chem. Soc., 114, 9457-64 (1992). 